\title{
Determination of the air separator circulation path parameters
}

\author{
Rinat Sharapov* \\ Moscow State University of Civil Engineering (National Research University), 129337, Moscow, \\ Russia
}

\begin{abstract}
The article discusses the separation process efficiency issue of the fine powders in an air separator. The aerodynamic scheme of the air separator is proposed and the schemes of the gas-material flow through the elements of the separator gas-material path are considered. The equations of the gas-material flow motion through the separator gas-material path elements are proposed. The calculation of the air separator various operating modes is proposed. The results of an approximate graphicalanalytical calculation of the gas-material path of the proposed aerodynamic scheme for the air separator are presented. A high convergence of theoretical positions with the performed experiments is shown.
\end{abstract}

\section{Introduction}

In the production of various building materials, their fine grinding is essential $[1,2]$. For this, various types of grinding plants are used [3-5]. In the production of cement, more than $50 \%$ of all consumed electricity is consumed for grinding $[1,6,7]$. At the same time, to improve the quality of the cement produced, air separators are widely used, which not only improve the quality of the cement itself, but also increase the technical and economic indicators of the entire production as a whole [8-11]. However, modern separators have a number of significant disadvantages, one of which is the insufficient efficiency of the separation process. Moreover, the efficiency of which is $50 \ldots 60 \%[12,13]$. To increase the efficiency in [14] it is proposed to change the aerodynamic operating mode of the separator, which improves the operating modes of the air separator.

\section{Theory}

To solve the aerodynamic problem of the motion scheme proposed in [14], we consider the movement of the gas-material flow through the tees of the tract itself. The gas-material path of the separator contains two tees (see Fig. 1). The tee 8, located in front of the separator, is an exhaust tee. It merges and mixes the streams of fresh air $Q_{1}$ and recirculated air $Q_{r}$, which returns to the separator (Fig. 1).

\footnotetext{
* Corresponding author: rinat.sharapoff@gmail.com
} 


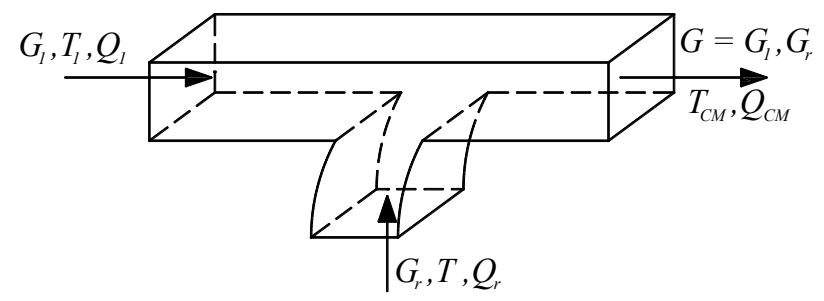

Fig. 1. Scheme of the exhaust tee located in front of the separator

In the supply tee 9 (see Fig. 1), the separation air flow after the fan is divided into a recirculation flow going to the separator and a stream going to the bag filter for cleaning (Fig. 2).

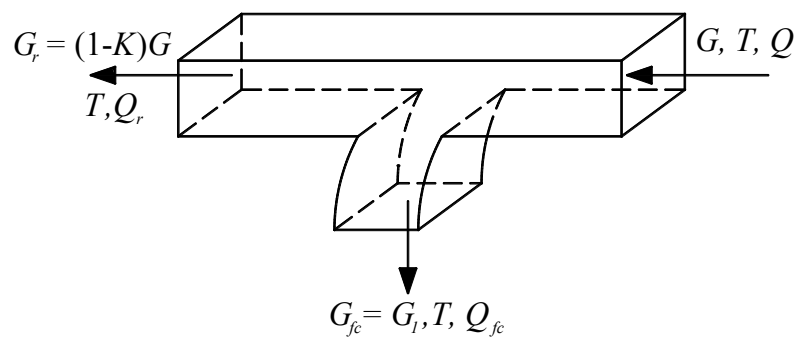

Fig. 2. Scheme of the supply tee located in front of the filter

Coefficients of teeslocal resistances related to the air velocity in the collection ducts under the previously accepted condition of all gas ducts' cross-sectional areas equality are determined by the ratios approximating the experimental data [15]:

- exhaust tee, lateral branch of the recirculation circuit:

$$
\zeta_{s}=1,55 r^{2}-2.888 r-0.90
$$

- exhaust tee, passage to the separator:

$$
\zeta_{p}=1.25 r^{2}+0.875 r+0.105
$$

Where

$$
r=\frac{Q_{1}}{Q_{m i x}}=\frac{Q_{1} / \rho(T)}{G / \rho\left(T_{m i x}\right)}=\frac{(1-K) T}{K T_{1}+(1-K) T}
$$

- supply tee, side branch to filter:

$$
\zeta_{b f}=1.39 s^{2}-1.74 s+0.84
$$

- supply tee, passage to the recirculation flue:

$$
\zeta_{c}=0.75 s^{2}-0.22 s-0.02
$$

Where $s$ is the volume fraction of air supplied to the filter for cleaning, $s=Q_{f i} / Q$.

From the condition of maintaining the air mass in tees, $\mathrm{kg}$ : 


$$
\begin{aligned}
& G_{1}+G_{r}=G, \\
& G=G_{r}+G_{f i}
\end{aligned}
$$

it follows that the mass flow rates of the supply air and the air going to the filter for cleaning are equal:

$$
G_{1}=G_{f i}
$$

Therefore

$$
s=\frac{Q_{f i}}{Q}=\frac{G_{f i} / \rho(T)}{G / \rho(T)}=\frac{G_{1}}{G}=K .
$$

In addition to tees, local resistances are created by other elements of the separator gas path: elbows $\left(\zeta_{c}=1.2\right)$, fresh air inlet to the branch pipe $\left(\zeta_{e n}=0.5\right)$, outlet of purified air from the filter to the atmosphere $\left(\zeta_{b x}=1\right)$, cracks and leaks through which there is an unorganized intake of fresh $\operatorname{air}\left(\zeta_{V}=4.73\right)$.

The above gas-material path of the air separator contains two main elements - a tee, from one there is an exhaust of dusty air, and from the other supply of fresh atmospheric air. This flue system and tee can be called a recirculation loop. There is also a main direction in this scheme, which can also be viewed as an external contour. The main direction of the separation complex includes an air separator, settling cyclones, a separation fan, a filter for cleaning dusty separation air, gas ducts connecting these elements and a branch pipe for supplying fresh air to the system. In the case of a closed rotary valve, fresh ambient air mainly enters the system and only the main direction works. In the case of an open rotary valve, the traditional circulation circuit works, i.e., the circulation circuit. In this case, the separation air coming out of it, enters the separator and part of the air is sucked in through various types of leaks in the pipeline.

With a partially closed rotary valve, the separator operates according to a mixed scheme. In this case, two directions are realized simultaneously: the circulation loop and the main direction.

To determine the aerodynamic scheme of the air separatorproposed design, taking into account the second Kirchhoff law, we obtain the following equations:

- to implement the main direction:

$$
\begin{aligned}
& \zeta_{e n} \frac{G_{1}^{2}}{2 \rho_{1} F_{e n}^{2}}+\zeta_{p s} \frac{G^{2}}{2 \rho_{m i x} F_{a r}^{2}}+\zeta_{s} \frac{G^{2} \rho_{s}}{2 \rho^{2} F_{s}^{2}}+\zeta_{c} \frac{G^{2} \rho_{c}}{8 \rho^{2} F_{c}^{2}} \\
& +2 \zeta_{K} \frac{G^{2} \rho_{a r}}{2 \rho^{2} F_{a r}^{2}}+\zeta_{b f} \frac{G^{2} \rho_{a r}}{2 \rho^{2} F_{a r}^{2}}+\Delta p_{f i}+\zeta_{e x} \frac{G_{1}^{2}}{2 \rho^{2} F_{e x}^{2}}=\Delta p_{f}(G) ;
\end{aligned}
$$

- for the implementation of the circulation circuit:

$$
\begin{aligned}
& \zeta_{s} \frac{G^{2} \rho_{s}}{2 \rho^{2} F_{s}^{2}}+\zeta_{c} \frac{G^{2} \rho_{c}}{8 \rho^{2} F_{c}^{2}}+2 \zeta_{K} \frac{G^{2} \rho_{a r}}{2 \rho^{2} F_{a r}^{2}}+\zeta_{p c} \frac{G^{2} \rho_{a r}}{2 \rho^{2} F_{a r}^{2}}+ \\
& +\zeta_{K} \frac{\left(G-G_{1}\right)^{2} \rho_{a r}}{2 \rho^{2} F_{a r}^{2}}+\zeta_{V} \frac{\left(G-G_{1}\right)^{2} \rho_{a r}}{2 \rho^{2} F_{a r}^{2}}+\zeta_{b c} \frac{G^{2}}{2 \rho_{\mathrm{CM}} F_{a r}^{2}}=\Delta p_{f}(G) .
\end{aligned}
$$


In the equations $(10,11) F_{\text {en }}, F_{a r}, F_{s}, F_{c}, F_{\text {ex }}$ of the area, respectively, of the crosssectional area of the branch pipe for the fresh air in flow, the gas ducts branch pipe crosssectional area, the cross-sectional area of the separatorbranch pipe, the cross-sectional area of the cyclonebranch pipe, the exhaust pipe cross-sectional area of the branch pipe; crosssectional area of the exhaust pipe; $\Delta p_{f}(G)$ the air mass flow equation.

The exact solution of the system of equations included in the mathematical model of the gas-material path of the separator is a complex problem that can be solved only by numerical methods.

To calculate the proposed system of an air separator operating according to a mixed aerodynamic scheme, let us consider a graphical-analytical method of approximate engineering calculation. When calculating, we will take into account that the cementtemperature fluctuates around $90 \ldots 105^{\circ} \mathrm{C}$.

The calculation of this separatoroperating mode is carried out in the following sequence:

1. We set $t=90{ }^{\circ} \mathrm{C}(T=273+90=363 \mathrm{~K})$;

2. We find the fresh air supply necessary to maintain this temperature (for the accepted initial data $G_{1}=16,3 \mathrm{~kg} / \mathrm{s}$ );

3. For various admissible values of the separation air flow rate (for the accepted initial data $Q=28-55 \mathrm{~m}^{3} /$ sor $\left.G\left(t=90{ }^{\circ} \mathrm{C}\right)=28.8 \ldots 56.6 \mathrm{~kg} / \mathrm{s}\right)$ we find the temperature of the mixed air flow in front of the separator and the density of the gas material flow in different parts of the duct and using the formulas (1-8) - the coefficients of teeslocal resistance;

4. Having determined the total pressure loss for the main line of the tract $\Delta p_{f}$ (the left side of equation (10)) for different values of the separation air flow rate, we build a graph of dependence $\Delta p_{f}(G)$, i.e., the main line aerodynamic performance;

5. In the same coordinates, we build the aerodynamic characteristic of the fan $\Delta p_{f}(G)$. The point of the graphs'intersection determines the flow rate of separation air that can be maintained in the network at a given temperature value of the separation process and the finished product;

6. To maintain the found operating mode of the main direction, it must be aerodynamically coordinated with the circulation circuit. Substituting the found values of the parameters into the equation (11), we find the required aerodynamic resistance of the rotary valve;

7. Repeating the above-performed calculation for the upper limit of the temperature range $t=105^{\circ} \mathrm{C}$, let us find the interval for adjusting the aerodynamic operating mode of the separator by throttling the circulation circuit using a rotary valve.

The results of an approximate graphical-analytical calculation of the separatorgasmaterial path can be refined by the method of successive approximations: according to the known flow rate of the supplied fresh air $G_{1}$. The results of an approximate graphicalanalytical calculation of the gas-material path of the separator can be refined by the method of successive approximations: according to the known flow rate of the supplied fresh air $G$ the value of the coefficient $K$ is determined, recalculation of the densities of the gas material flow in different parts of the duct is carried out, the resistances of the tees are specified. All of the above-mentioned parameters are fixed at a level corresponding to the previously found flow rate $G$. The equation (10) is then reduced to a quadratic equation for the separation air flow rate.

Solving this equation, we get a new, more accurate value $G$, which is again used to calculate the separator pathparameters. The calculations show that this computational process converges quickly and one or two iterations are sufficient to obtain a result with an accuracy sufficient for engineering applications.

Let us consider the calculation of the separator Sturtevant SD-70operation mixed mode which can be realized as a result of the reconstruction proposed in this workas an example. 
Initial data: $G_{m}=120 \mathrm{t} / \mathrm{h}=33.3 \mathrm{~kg} / \mathrm{s} ; k_{\mathrm{c}}=2.5 ; \eta_{\mathrm{o}}=0.9 ; t_{\mathrm{a}}=25^{\circ} \mathrm{C} ; t=105{ }^{\circ} \mathrm{C} ; \rho=0.934$ $\mathrm{kg} / \mathrm{m}^{3}$. The initial mass flow ratevalue of the separation air: $G=18.36 \mathrm{~kg} / \mathrm{s}$. Corresponding volumetric flow $Q==G / \rho=19.66 \mathrm{~m}^{3} / \mathrm{s}$. $\mathrm{m}^{2}$.

The cross-sectional area of all gas ducts is assumed to be the same and equal to: $F_{a r}=1$

\section{Solution:}

1. We find the concentration of the material in the air at the inlet to the separator

$$
Z_{m}=G_{m} / Q=1.694 \mathrm{~kg} / \mathrm{m}^{3}
$$

2. We find the average density of the gas material flow in different parts of the tract:

- in the separator $\rho s=2.16 \mathrm{~kg} / \mathrm{m}^{3}$;

- in a cyclone $\rho_{c}=1.34 \mathrm{~kg} / \mathrm{m}^{3}$;

- in gas ducts after cyclone $\rho_{a r}=1 \mathrm{~kg} / \mathrm{m}^{3}$.

3. We find the flow rate of fresh air required to maintain the specified temperature of the separation air $t=105^{\circ} \mathrm{C}$ :

$$
G_{1}=9.18 \mathrm{~kg} / \mathrm{s}
$$

4. We calculate the mass fraction of the supply air in the total separation air flow:

$$
K=G_{1} / G=0.5
$$

5. We find the temperature of the mixed flow of fresh and circulating air at the inlet to the separator:

$$
T_{\text {mix }}=338 \mathrm{~K}\left(t_{\text {mix }}=65^{\circ} \mathrm{C}\right) .
$$

6. Using the formulas (1-8), we find the coefficients of local resistance of the exhaust tee in front of the separator:

$$
\zeta_{b c}=0.22, \quad \zeta_{p s}=0.203,
$$

and a supply tee in front of the filter:

$$
\zeta_{b f}=0.32, \quad \zeta_{p c}=-0.06 .
$$

7. Substituting the given and found values of the parameters into equation (10), we obtain the following equation for the separation air flow rate:

$$
32.05 G^{2}-136.2 G-8964.4=0 .
$$

The solution to this equation at $G=19 \mathrm{~kg} / \mathrm{s}$. Using the method of successive approximations, the mass flow rate of the separation air is refined to the value $G=19.15$ $\mathrm{kg} / \mathrm{s}$.

8. Substituting the found value $G$ into the equation (11), we find the rotary valvelocal resistance coefficientvalue, necessary to maintain the specified aerodynamic operating mode of the separator: $\zeta_{V}=26.29$.

9. Next, we find that the required value of the rotary valve local resistance coefficient is achieved at an angle of its rotation $\alpha=44.5^{\circ}$.

10. The air pressure in front of the separator is determined by the ratio: 


$$
P_{s}=\zeta_{e n} \frac{G_{1}^{2}}{2 \rho_{1} F_{e n}^{2}}+\zeta_{p s} \frac{G^{2}}{2 \rho_{m i x} F_{a r}^{2}} .
$$

\section{Results}

Using the method described above, using the example of the Sturtevant SD separator, the possibility of controlling the flow rates of separation and supply air, the temperature of the separation process and the finished product, as well as the pressure (vacuum) at the inlet to the separator by throttling with a rotary valve was investigated. It was found that the mixed mode of separatoroperation (circulation of the separation air, supplemented by the fresh airinflow) occurs only at a certain resistance of the rotary valve. For the considered example local lost coefficient ofthe rotary valve must satisfy the condition $\zeta_{V} \geq 5.4$. The calculations also show that with a constant fan operation, an increase in the rotary valve resistance and a transition to a mixed separation mode leads to a decrease in the separation air flow rate up to $7 \%$, and also leads to a change in its composition, i.e., mass fraction of fresh air $K$.

When the rotary valve is open, the air temperature is $t=105^{\circ}$ Cat pressure in front of the separator $p=-52 \mathrm{~Pa}=-5.3$ mmwater column.

\section{Conclusions}

At the angle of rotation $\alpha=85^{\circ}$ the direct-flow mode of the separatoroperation is established, in which its entire path works under vacuum (the vacuum in front of the separator reaches the highest value and is $-142 \mathrm{~Pa}$ ) and the separation air temperature is reduced to $90{ }^{\circ} \mathrm{C}$.

Fig. 3 shows the temperature of the cement depending on the rotationangle of the damper between the tees. Fig. 4 shows the influence on the pressure in the air separator of the rotationangle of the damper between the tees. The graphs are constructed by solving the equations (10) ... (14).

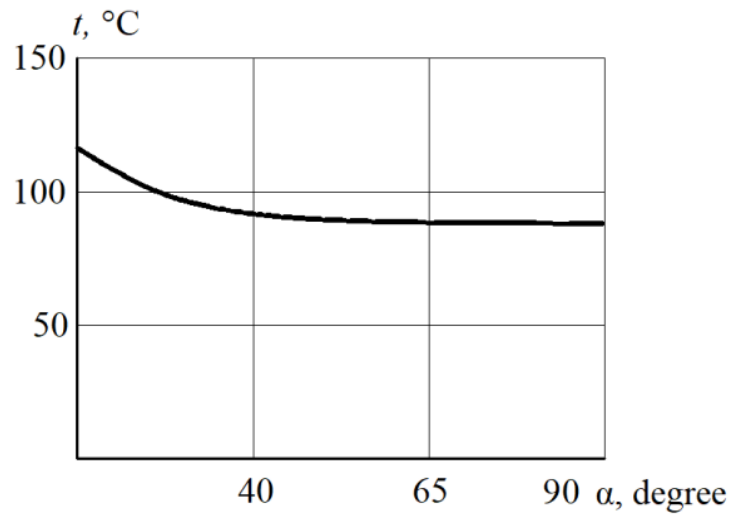

Fig. 3. Cement temperature depending on the rotation angle of the damper between the tees 


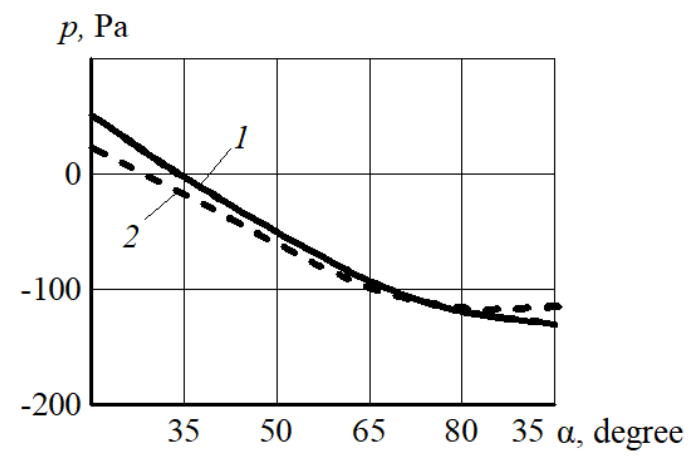

Fig. 4. Influence of the rotation angle of the damper between the tees on the pressure in the air separator: 1 - calculated data; 2 - experimental data

\section{References}

1. W. H. Duda, Cement-data-book (Band 1, Wiesbaden, Bauverlag, Berlin, 1985).

2. R.R. Sharapov, IOP Conference Series: Materials Science and Engineering. International Conference on Mechanical Engineering and Applied Composite Materials 012048 (2018).

3. Grinding trends in the cement industry, ZKG International 4 (2010).

4. U. Karsunke, Improvement in new and existing mills, Proc. Of 8th International Petrocem conference, St. Petersburg, April, (2014).

5. S.Y. Lozovaya, N.M. Lozovoyv, V.A. Uvarov, L.V. Ryadinskaya, R.R. Sharapov, International Journal of Pharmacy and Technology 8 (4), 24733-24747 (2016).

6. M. Gosis, Cement and its application 3, 36-41 (2014).

7. R.R. Sharapov, I.V. Shrubchenko, A.M. Agarkov, International Journal of Applied Engineering Research 10 (12) (2015)

8. R.R. Sharapov, V.S. Prokopenko, World Applied Sciences Journal 25 (3) (2013)

9. T. Subeggve, Zement Kalk Gips International 2 64-69 (2004).

10. E. Furukawa, T. Onuma, Misaka, Int. Symp. on powder technology, Kyoto (1981).

11. R.R. Sharapov, MATEC Web of Conferences 251, (2018).

12. N.A. Madlool, R. Saidur R., M.S. Hossain, N.A. Rahim, Reneweable and Sustainable Energy Rev. 15, 2042-2060 (2011).

13. V. I. Telichenko, R. R. Sharapov, S. Y. Lozovaya, V.I. Skel, MATEC Web of Conferences 5. "5th International Scientific Conference "Integration, Partnership and Innovation in Construction Science and Education", IPICSE 2016". (2016)

14. R.R. Sharapov, IOP Conference Series: Materials Science and Engineering 913 (4), (2020).

15. I.E. Idelchik, Handbook of hydraulic resistances (Mechanical engineering, Moscow, 1975). 